\title{
A Case-Control Study of Maternal Gestational Weight Gain and Newborn Birthweight and Birthlength in Twin Pregnancies Complicated by Preeclampsia
}

\author{
B. Luke ${ }^{1,3,5}$, L. Keith 2,3,4, J.A. Lopez-Zeno 2,6 , F.R. Witter', E. Saquil ${ }^{3}$ \\ ${ }^{1}$ Division of Maternal-Fetal Medicine, Department of Gynecology and Obstetrics, Johns Hop- \\ kins University School of Medicine, Baltimore, Maryland; ${ }^{2}$ Department of Obstetrics and Gy- \\ necology, Northwestern University Medical School and Prentice Women's Hospital of North- \\ western Memorial Hospital, Chicago; ${ }^{3}$ Center for Study of Multiple Births, Chicago; ${ }^{4}$ Jeanette \\ Kennelly Kroch Center for Twin Studies, Northwestern Memorial Hospital, Chicago; ${ }^{5}$ Section \\ of Reproductive and Perinatal Epidemiology, Department of Obstetrics and Gynecology, Rush \\ Medical College, Rush-Presbyterian-St. Luke's Medical Center, Chicago, Illinois; ${ }^{6}$ Department \\ of Obstetrics and Gynecology, The George Washington University School of Medicine, \\ Washington, D.C.
}

\begin{abstract}
To evaluate the influence of rate of gestational weight gain on newborn birthweight and birthlength in twin gestations complicated by preeclampsia, 74 cases of preeclampsia in twin pregnancy were matched to 148 non-preeclamptic twin controls for maternal race, height, pregravid weight, age and length of gestation. Total weight gain was significantly higher for all cases versus controls and for mild cases versus controls. However, the rate of early weight gain was lower for severe cases and severe cases with thrombocytopenia compared to their controls. Mean birthweight and birthlength did not differ between cases and controls, although the proportion with birthlength below the 10th percentile was significantly higher among cases than controls. In addition, the proportion of birthweights and birthlengths $<10$ th percentile was significantly higher among cases than controls. These findings suggest that inadequate early weight gain in twin gestations complicated by preeclampsia results in retarded birthlength and birthweight. The implication of these findings are discussed.
\end{abstract}

Key words: Gestational Weight gain, Preeclampsia, Twins

\section{INTRODUCTION}

Several investigations have focused on the association between patterns of gestational weight gain in singleton pregnancies and outcome, particularly preterm delivery and low birthweight (LBW) $[1,8,15]$. Others have sought to clarify the cause-and-effect relation- 
ship, if any, between patterns of weight gain and preeclampsia. Some early studies merely evaluated total weight gain throughout the pregnancy and erroneously concluded that higher weight gains were the cause rather than the result of preeclampsia. Opinions differed markedly about specific patterns of gain. Sudden gain was thought by some authors to precipitate toxemia [4,7]; others suggested that inadequate gain in early pregnancy (variously defined) was associated with a higher incidence of the disease. For example, in an evaluation of 2502 normal pregnancies and 433 women with preeclampsia and eclampsia, Stander and Pastore [17] concluded that those women who had preeclampsia and eclampsia had lower gestational weight gains through 30 weeks of pregnancy. This observation was subsequently confirmed by Tompkins et al [22] in their study which included 65 patients who developed toxemia. Failure to gain even an average amount of weight by the third trimester ( 28 weeks) was associated with an increased incidence of toxemia.

Preeclampsia occurs more frequently and with greater severity in twin gestations [9, 12]. In addition, preterm delivery and low birthweight are more common among multiples. Recently, higher total gestational weight gain in women pregnant with twins was shown in two studies to exert a beneficial effect on birthweight and length of gestation in the absence of maternal preeclampsia $[6,14]$. Using a case-control method, we examined the influence of the rate of gestational weight gain (early, late, and total) on birthweight and birthlength in twin gestations complicated by preeclampsia. We wanted to determine if differences in birthlength and birthweight were present in infants of normal twin pregnancies and those complicated by PIH by patterns of maternal weight gain.

\section{MATERIALS AND METHODS}

Cases and controls for this study were obtained through the twin data bases at the Johns Hopkins University School of Medicine, Department of Gynecology and Obstetrics (350 twin births from 1979-1989) and the Northwestern University Medical School, Department of Obstetrics and Gynecology (250 twin births from 1983-1989). A total of 74 cases of preeclampsia in twin gestations were identified from the Johns Hopkins Twin Data Base and categorized using the American College of Obstetricians and Gynecologists' 1986 classification of hypertensive disorders in pregnancy for mild preeclampsia, severe preeclampsia, and severe preeclampsia with thrombocytopenia [2]. These classes will be used throughout the analyses that follow although it is recognized that the appearance of thrombocytopenia is not related to the degree of hypertension or its longevity, but rather represents an index of disease severity. Each case was matched to two nonpreeclampsia twin controls (one each from the Johns Hopkins Twin Data Base and one from the Northwestern Twin Data Base), for maternal race (black or white), parity (primipara or multipara), height ( \pm 2 inches), pregravid weight ( \pm 5 pounds), age $( \pm 2$ years), and length of gestation in completed weeks from last menstrual period $( \pm 2$ weeks). Because information on maternal education was missing in more than $25 \%$ of cases, it was not included in this study.

These variables were chosen because of their known correlation with birthweight. By selecting them, we hoped to more clearly evaluate the association between weight gain, rates of gain and birthweight in twin gestations with preeclampsia (cases) compared to 
twin gestations without preeclampsia (controls). Maternal pregravid weight was obtained directly from each mother's prenatal record as reported at the first prenatal visit. Although the accuracy of this information is often a matter of clinical concern, carefully conducted studies in populations, ranging from pregnant adolescents in special clinics to adult women in the Health Insurance Study of the Rand Corporation, attest to the reliability and validity of this recall data $[18,19]$. Data abstracted from the newborn medical record of cases and controls included birthweight and birthlength. Maternal and newborn charts were abstracted by three members of the research team (BL, JLZ, ES).

Table 1 - Description of characteristics of study cases and matched controls (mean \pm standard deviation)

\begin{tabular}{lrccccc}
\hline & N & $\begin{array}{c}\text { Maternal } \\
\text { age } \\
\text { (Years) }\end{array}$ & $\begin{array}{c}\text { Maternal } \\
\text { height } \\
\text { (Inches) }\end{array}$ & $\begin{array}{c}\text { Pregravid } \\
\text { weight } \\
\text { Pounds) }\end{array}$ & $\begin{array}{c}\text { Pregravid } \\
\text { weight-for- } \\
\text { height } \\
\text { (Percent)* }\end{array}$ & Gestation \\
(Weeks) \\
\hline All Cases & 74 & $26.1 \pm 6.3$ & $64.5 \pm 2.5$ & $140.6 \pm 32.5$ & $105.4 \pm 23.3$ & $35.2 \pm 3.3$ \\
All Controls & 148 & $26.5 \pm 6.9$ & $64.2 \pm 2.8$ & $141.4 \pm 28.9$ & $108.9 \pm 20.1$ & $35.0 \pm 3.0$ \\
\hline Mild Cases & 54 & $25.4 \pm 6.4$ & $64.5 \pm 2.5$ & $134.3 \pm 30.0$ & $103.0 \pm 21.6$ & $35.7 \pm 2.9$ \\
Mild Controls & 108 & $26.8 \pm 7.2$ & $64.3 \pm 2.4$ & $137.9 \pm 39.8$ & $105.4 \pm 24.4$ & $35.6 \pm 3.1$ \\
Severe Cases & 20 & $28.2 \pm 5.9$ & $64.5 \pm 2.6$ & $147.6 \pm 37.7$ & $112.0 \pm 27.1$ & $33.7 \pm 3.9$ \\
Severe Controls & 40 & $25.8 \pm 6.0$ & $64.5 \pm 3.0$ & $149.8 \pm 30.3$ & $115.4 \pm 23.2$ & $33.8 \pm 3.7$ \\
\hline
\end{tabular}

\begin{tabular}{lrrrrrr} 
Severe Cases with & & & & & & \\
Thrombocytopenia & 9 & $31.3 \pm 2.7$ & $62.2 \pm 2.6$ & $147.9 \pm 38.3$ & $111.9 \pm 28.9$ & $32.6 \pm 2.6$ \\
Controls & 18 & $29.9 \pm 5.6$ & $64.7 \pm 3.0$ & $148.3 \pm 32.2$ & $112.1 \pm 26.3$ & $32.9 \pm 2.3$ \\
\hline
\end{tabular}

* Based on the Metropolitan Insurance standards of desirable weight, Statistical Bulletin of the Metropolitan Life Insurance Co, 1959. 40:1.

Exclusion criteria for both cases and controls included the following conditions, all of which are known to affect intrauterine growth: alcohol/drug use, chronic hypertension, diabetes (pregravid or gestational), and major medical illnesses of the cardiac, renal, or respiratory systems. The results of this match are given in Table 1. Rates of gestational weight gain in pounds per day were calculated in three ways. The rate of total gain was based upon the difference between maternal pregravid weight and the recorded weight at the last prenatal visit, which was almost always within one week of delivery, divided by days from LMP. The rate of early gestational weight gain was calculated as the difference between maternal pregravid weight and the recorded prenatal weight at 24 weeks (168 days from LMP), divided by days from LMP. The rate of late gestational weight gain was calculated as the difference between the recorded prenatal weight at 24 weeks gestation and the last recorded prenatal weight before delivery, divided by the number of days from 24 weeks to the day of delivery. The prenatal weight at 24 weeks 
gestation, or 168 days from LMP, was taken directly from the chart or, if missing, was interpolated based on recorded weight plus or minus two weeks. These data are presented in Table 2.

Table 2 - Comparison of rates of total, early, and late gestational weight gain ( \pm SD) for twin pregnancies with PIH vs controls

\begin{tabular}{|c|c|c|c|c|c|}
\hline $\mathbf{N}$ & $\begin{array}{l}\text { Total weight } \\
\text { gain (lb) }\end{array}$ & $\begin{array}{c}\text { Total gain } \\
\text { (lb/day) } \\
\text { LMP• } \\
\text { to ADC•• }\end{array}$ & $\begin{array}{l}\text { Early gain } \\
\text { (lb/day) LMP } \\
\text { to day } 168\end{array}$ & $\begin{array}{c}\text { Late gain } \\
\text { (lb/day) day } \\
168 \text { to ADC }\end{array}$ & $\begin{array}{l}\mathrm{p} \\
\text { value** }\end{array}$ \\
\hline
\end{tabular}

\begin{tabular}{lrrrrrr} 
& & & & $\mathrm{I}: \mathrm{M}$ \\
All Cases & 74 & $\mathrm{~A}[46.5 \pm 15.7$ & ${ }^{\mathrm{E}}[0.194 \pm 0.06$ & ${ }^{\mathrm{I}}[0.143 \pm 0.07$ & ${ }^{\mathrm{M}}[0.306 \pm 0.16$ & $\mathrm{p}<0.0001$ \\
All Controls & 148 & {$[37.9 \pm 14.9$} & {$[0.169 \pm 0.06$} & {$[0.139 \pm 0.07$} & {$[0.205 \pm 0.10$} & $\mathrm{p}<0.0001$ \\
\hline
\end{tabular}

\begin{tabular}{|c|c|c|c|c|c|c|}
\hline Mild Cases & 54 & ${ }^{\mathrm{B}}[48.9 \pm 15.0$ & ${ }^{\mathrm{F}}[0.200 \pm 0.06$ & ${ }^{\mathrm{J}}[0.146 \pm 0.07$ & $\begin{array}{l}\mathrm{N}[0.310 \pm 0.18 \\
{[0.280 \pm 0.10}\end{array}$ & $\begin{array}{l}\mathrm{J}: \mathrm{N} \\
\mathrm{p}<0.0001 \\
\mathrm{n}<0.0001\end{array}$ \\
\hline Mild Controls & 108 & {$[37.5 \pm 14.6$} & {$[0.166 \pm 0.06$} & {$[0.135 \pm 0.07$} & {$[0.280 \pm 0.10$} & $\mathrm{p}<0.0001$ \\
\hline $\begin{array}{l}\text { Severe Cases } \\
\text { Severe Controls }\end{array}$ & $\begin{array}{l}20 \\
40\end{array}$ & $\begin{array}{r}{ }^{c}[40.1 \pm 16.3 \\
{[39.1 \pm 15.6}\end{array}$ & $\begin{array}{r}{ }^{\mathrm{G}}[0.178 \pm 0.07 \\
{[0.176 \pm 0.06}\end{array}$ & $\begin{array}{r}{ }^{\mathrm{k}}[0.135 \pm 0.06 \\
{[0.152 \pm 0.08}\end{array}$ & $\begin{array}{r}{ }^{\circ}[0.279 \pm 0.12 \\
{[0.198 \pm 0.09}\end{array}$ & $\begin{array}{l}\mathrm{K}: \mathrm{O} \\
\mathrm{p}<0.0001 \\
\mathrm{p}<0.02\end{array}$ \\
\hline $\begin{array}{l}\text { Severe Cases with } \\
\text { Thrombocytopenia } \\
\text { Controls }\end{array}$ & $\begin{array}{r}9 \\
18\end{array}$ & $\begin{array}{r}\mathrm{D}[36.4 \pm 14.0 \\
{[42.8 \pm 13.6}\end{array}$ & $\begin{array}{r}{ }^{\mathrm{H}}[0.180 \pm 0.08 \\
{[0.199 \pm 0.06}\end{array}$ & $\begin{array}{r}\mathrm{L}[0.138 \pm 0.06 \\
{[0.179 \pm 0.07}\end{array}$ & $\begin{array}{l}\mathrm{P}[0.279 \pm 0.14 \\
{[0.204 \pm 0.08}\end{array}$ & $\begin{array}{l}\mathrm{L}: \mathrm{P} \\
\mathrm{p}<0.03 \\
\text { ns }\end{array}$ \\
\hline $\begin{array}{l}\text { - } \mathrm{LMP}=\text { last menst } \\
\bullet \mathrm{ADC}=\text { actual dat } \\
* \mathrm{p} \text { value for } \mathrm{t} \text { test } \\
* \text { p value for paire } \\
\mathrm{ns}=\text { not significant }\end{array}$ & tes & $\begin{array}{l}\text { *A. } \mathrm{p}<0.0001 \\
\text { B. } \mathrm{p}<0.0001 \\
\text { C. ns } \\
\text { D. ns } \\
\text { od } \\
\text { finement } \\
\text { controls) } \\
\text { :M, J:N, K:O, }\end{array}$ & $\begin{array}{l}\text { E. ns } \\
\text { F. ns } \\
\text { G. ns } \\
\text { H. ns } \\
\\
\text { :P) }\end{array}$ & $\begin{array}{l}\text { I. ns } \\
\text { J. ns } \\
\text { K. ns } \\
\text { L. ns }\end{array}$ & $\begin{array}{l}\text { M. } p<0.0001 \\
\text { N. } p<0.001 \\
\text { O. } p<0.0035 \\
\text { P. ns }\end{array}$ & \\
\hline
\end{tabular}

A gestational age-specific newborn singleton standard [10] developed at the Johns Hopkins Hospital in Baltimore was used to evaluate the birthweight and birthlength of the twin infants in this study. The singleton infants included in this standard were delivered at the Johns Hopkins Hospital between January 1, 1979 and December 31, 1987 and were free of congenital anomalies and alive at the time of their discharge from the nursery. Their gestational age at birth was based on completed weeks from LMP or was established by best obstetrical estimate, which incorporates data from the last known menstrual period, ultrasound examination(s), the time of the first auscultation of fetal heart sounds, and early bimanual examination to yield a composite estimate of gestational age at the time of delivery. Infants for whom a gestational age could not be deter- 
mined or for whom birthweight data was missing were excluded. Infants other than white or black race were excluded, because these two racial groups comprise almost the entire Johns Hopkins Hospital population. The final singleton gestational age-specific newborn standard included 19,072 infants of whom $50.9 \%$ were male, $49.1 \%$ female, $66.3 \%$ black and $33.7 \%$ white. Using this overall gestational age-specific newborn standard, specific singleton standards were then developed, stratified by infant sex and race, and by both sex and race in combination. Case and control infants were categorized by mean birthweight and birthlength, as well as proportion with birthweight and birthlength above and below the 10th percentile for gestational age. Intratwin birthweight discordance (expressed as a percentage of the weight of the larger twin) greater than $15 \%$ was also calculated for twin infants of cases and controls. This value was chosen because higher degrees of discordance are associated with increased morbidity and mortality [5, 13]. These data are presented in Table 3.

Table 3 - Comparison of birthweight and birthlength of infants of cases with PIH vs infants of controls

\begin{tabular}{|c|c|c|c|c|c|c|c|}
\hline & $\mathrm{N}$ & $\begin{array}{l}\text { Birthweight* } \\
\pm \mathrm{SD} \text { (gm) }\end{array}$ & $\begin{array}{l}\text { Birthweight** } \\
<10 \text { th \%ile }\end{array}$ & $\begin{array}{l}\text { Intrapair wt. } \\
\text { discordancy } \\
>15 \% \\
(\%)\end{array}$ & $\begin{array}{l}\text { Birthlength* } \\
\pm \mathrm{SD}(\mathrm{cm})\end{array}$ & $\begin{array}{l}\text { Birthlength** } \\
<10 \text { th \%oile }\end{array}$ & $\begin{array}{l}\text { Wt. and } \\
\text { lgth** } \\
<10 \text { th \%oile }\end{array}$ \\
\hline All Cases & 148 & ${ }^{A}[2294 \pm 673$ & $\mathrm{E}[36 \%$ & ${ }^{\mathrm{I}}[41 \%$ & ${ }^{\mathrm{M}}[45.7 \pm 4.3$ & $\mathrm{Q}[34 \%$ & $\mathrm{U}[20 \%$ \\
\hline All Controls & 296 & {$[2248 \pm 635$} & {$[23 \%$} & {$[22 \%$} & {$[45.7 \pm 4.1$} & {$[24 \%$} & {$[11 \%$} \\
\hline Mild Cases & 108 & ${ }^{\mathrm{B}}[2400 \pm 643$ & $\mathrm{F}[36 \%$ & $\mathrm{j}[41 \%$ & ${ }^{N}[46.4 \pm 4.0$ & ${ }^{\mathrm{R}}[33 \%$ & $\mathrm{v}[22 \%$ \\
\hline Mild Controls & 216 & {$[2318 \pm 601$} & {$[27 \%$} & {$[22 \%$} & {$[45.7 \pm 4.4$} & {$[26 \%$} & {$[12 \%$} \\
\hline Severe Cases & 40 & ${ }^{c}[1984 \pm 721$ & $\mathrm{G}[35 \%$ & $\mathrm{K}[40 \%$ & ० $[43.7 \pm 4.6$ & $\mathrm{s}[37 \%$ & ${ }^{w}[10 \%$ \\
\hline Severe Controls & 80 & {$[2058 \pm 687$} & {$[11 \%$} & {$[22 \%$} & {$[44.6 \pm 4.5$} & {$[17 \%$} & {$[8 \%$} \\
\hline
\end{tabular}

\begin{tabular}{|c|c|c|c|c|c|c|c|}
\hline Severe Cases with & 18 & $\mathrm{D}[1943 \pm 727$ & ${ }^{\mathrm{H}}[28 \%$ & ${ }^{\mathrm{L}}[33 \%$ & ${ }^{\mathrm{P}}[44.0 \pm 4.4$ & $\mathrm{T}[19 \%$ & $\mathrm{x}[11 \%$ \\
\hline Controls & 36 & {$[2033 \pm 473$} & {$[0 \%$} & {$[11 \%$} & {$[45.0 \pm 3.4$} & {$[3 \%$} & {$[0 \%$} \\
\hline $\begin{array}{l}* \mathrm{t} \text { test } \\
* * \chi^{2} \text { test } \\
\mathrm{ns}=\text { not significant }\end{array}$ & & $\begin{array}{l}\text { A. } \mathrm{ns} \\
\text { B. ns } \\
\text { C. ns } \\
\text { D. ns }\end{array}$ & $\begin{array}{l}\text { E.p }<0.006 \\
\text { F. ns } \\
\text { G.p }<0.005 \\
\text { H.p }<0.005\end{array}$ & $\begin{array}{l}\text { I.p }<0.005 \\
\text { J.p }<0.012 \\
\text { K.ns } \\
\text { L. ns }\end{array}$ & $\begin{array}{l}\text { M. ns } \\
\text { N. ns } \\
\text { O. ns } \\
\text { P. ns }\end{array}$ & $\begin{array}{l}\text { Q.p }<0.05 \\
\text { R. ns } \\
\text { S.p }<0.05 \\
\text { T. ns }\end{array}$ & $\begin{array}{l}\text { U.p }<0.012 \\
\text { V.p }<0.03 \\
\text { W.ns } \\
\text { X.ns }\end{array}$ \\
\hline
\end{tabular}

The following statistical methods were used. The t test was used to evaluate the differences in continuous variables between cases and controls. The paired t test was used to evaluate the difference between mean early and mean late gestational weight gains within the same group. The chi-square test, with Yate's continuity correction, was used to evaluate differences in proportions of categorical variables between cases and controls. Results for all analyses were considered significant if the twotailed $P$ value was less than 0.05 . 


\section{RESULTS}

As shown in Table 1, it was possible to match cases and controls very closely for maternal age, height, pregravid weight, and length of gestation, in addition to race and parity. The mean pregravid weight of mild cases was about 10 pounds lighter than that of both severe cases and severe cases with thrombocytopenia. The mean length of gestation for mild cases was about 2 weeks longer than for severe cases and about 3 weeks longer than for severe cases with thrombocytopenia. Cases and controls had similar rates of smoking $(15 \%)$ and similar rates of cesarean delivery (73\% for all cases and $76 \%$ for all controls, including $72 \%$ and $70 \%$ for moderate cases and controls respectively; $75 \%$ and $90 \%$ for severe cases and controls respectively; and $89 \%$ each for severe cases with thrombocytopenia and their controls (data not shown in table)).

The mean total weight gain and the mean rates of early, late, and total gestational weight gain for cases and controls are presented in Table 2. Mean total weight gain was greater for all cases vs all controls $(8.6 \mathrm{lb}$ difference, $\mathrm{p}<0.0001)$, and for mild cases vs their controls $(11.4 \mathrm{lb}$ difference, $\mathrm{p}<0.0001)$. For severe cases and controls, mean total weight gain was similar (1.0 lb difference, ns). For severe cases with thrombocytopenia, mean total gain was $6.4 \mathrm{lb}$ less than for controls (not significant). Although differences in the respective mean rates of total gain were not statistically significant, several trends were apparent. The mean rate of total gain was higher for all divisions of cases, compared to controls, except for severe cases with thrombocytopenia. Moreover, mean rates of early gain were higher for all cases and mild cases compared to their respective controls, but were lower by $12.6 \%$ and $29.6 \%$ respectively, for severe cases and severe cases with thrombocytopenia, compared to their controls. The mean rate of late gestational weight gain was approximately $50 \%$ higher for all cases versus all controls $(0.310 \mathrm{lb} /$ day vs $0.205 \mathrm{lb} /$ day, $\mathrm{p}<0.001)$ and for severe cases compared to their controls $(0.297 \mathrm{lb} / \mathrm{day}$ vs $0.198 \mathrm{lb} /$ day, $\mathrm{p}<0.0035)$. The rate of late gestational weight gain was about $36 \%$ higher for severe cases with thrombocytopenia compared to their controls $(0.279 \mathrm{lb} /$ day vs $0.204 \mathrm{lb} /$ day), but due to small numbers, this difference was not statistically significant. Within groups, the rate of early versus late gain was significantly higher for cases compared to controls. The rate of late gain was more than twice the rate of early gain for all cases and after stratification by severity of disease. In contrast, among controls the rate of late gain was only $15-30 \%$ higher than their rate of early gain.

Data regarding birthweight, birthlength, and birthweight discordance are given in Table 3. Mean birthweight and birthlength did not differ statistically between infants of cases and controls. However, intrauterine growth retardation (IUGR, defined as birthweight or birthlength below the 10th percentile for gestational age) occurred more frequently among infants of cases, particularly infants of severe cases and severe cases with thrombocytopenia, compared to infants of controls. The incidence of IUGR (weight) was $57 \%$ higher among infants of all cases compared to infants of all controls (36\% vs $23 \%, \mathrm{p}<0.006$ ) and more than $200 \%$ higher among infants of severe cases compared to infants of their controls $(35 \%$ vs $11 \%, \mathrm{p}<0.005)$. Among infants of severe cases with thrombocytopenia, the incidence of IUGR was $28 \%$ compared to $0 \%$ among infants of their controls $(\mathrm{p}<0.005)$. A similar pattern of IUGR was also found for birthlength. The incidence of IUGR was more than $40 \%$ higher among infants of cases compared to infants of their controls $(34 \%$ vs $24 \%, \mathrm{p}<0.05)$; more than twice as high among in- 
fants of severe cases compared to infants of their controls $(37 \%$ vs $17 \%, p<0.05)$; and fivefold higher among infants of severe cases with thrombocytopenia compared to infants of their controls ( $19 \%$ vs $3 \%$, ns.).

\section{DISCUSSION}

This study differs from prior studies of preeclampsia in twins in several ways. To our knowledge, it is the first case control design in which each case was matched to two nonpreeclamptic twin controls. Second, the combination of cases and controls from two institutions permitted us to match each for the major factors known to influence intrauterine growth (race, parity, pregravid weight and length of gestation). The purpose of this match was to study the effects of weight gain and, in particular, the pattern of gain associated with preeclampsia on intrauterine growth. Third, by restricting the number of calendar years from which cases and controls were selected, we attempted to avoid the temporal changes in diagnostic and therapeutic modalities that might have been present had the study been carried out at one institution only, but for 20 or more years. Finally, by matching for gestational age each case and its controls, we attempted to avoid specific physician attitudes toward induction of labor as part of the therapy for preeclampsia.

A major focus of prior research on preeclampsia has been to examine weight gain from a "cause and effect" point of view, rather than examining the effect, if any, of either total gain or of differential rates of gain on perinatal outcome. Although it was acknowledged that infants born to women with PIH were ill, specific growth deficits that may have resulted from preeclampsia have not characterized [11]. We believe twin gestations may provide a model in which to verify the presence of such deficits, because preeclampsia may superimpose a second insult on infants already destined to deviate from normal singleton growth patterns [10]. Our findings of significantly more IUGR with respect to weight, length, and both weight and length in infants of cases compared to those of controls (Table 3 ) gives credence to this possibility, particularly in view of the strict matching criteria used.

In this study, both the rate and total amount of weight gain were greater in cases than controls (for all cases, mild cases and severe cases), a finding which has been reported by others over fifty years ago $[4,7,17]$. By evaluating the proportion of birthweights and birthlengths below the 10th percentile, the association between early versus late gains and IUGR in infants born to mothers with preeclampsia could be determined. Although studies conducted prior to 1955 documented that lower early prenatal weight gain is associated with a higher incidence of subsequent PIH, none have related this finding to impaired birthweight or birthlength. Our finding of increased stunting of both birthweight and birthlength paralleling disease severity suggests that infants born to women with peeclampsia have undergone a double insult during prenatal growth which can not be completely explained by shorter gestation alone.

Our finding of retarded birthlength was unexpected. According to Tanner [21], peak velocity of length growth occurs at about 20 weeks gestation, which is prior to the usual onset of symptoms of preeclampsia ( 24 weeks). This observation suggests the possibility that subclinical changes in the intrauterine environment may occur before the onset of 
rapid weight gain - one of the traditional markers of preeclampsia. It is possible that these effects are related to placental dysfunction. Placentas from women with preeclampsia are characterized by compromised perfusion, premature aging and the absence of specific lesions pathognomonic of preeclampsia $[3,16]$.

We propose the following theoretical framework to explain the associations we have shown. First, inadequate early weight gain may lead to poor placental implantation and development. Second, in certain women, placental dysfunction, compounded by preeclampsia, may lead to general impairment of fetal growth. Third, in twins, this effect is exaggerated, and results in significant reduction in birthweight and length. This theoretical framework is in accord with Young's hypothesis that low weight gain during early pregnancy results in vascular and placental inadequacy and subsequent IUGR [23].

The framework we propose implies that IUGR present at birth among twins whose mothers had preeclampsia may reflect an imprint of the maternal disease and may impair the rate and pattern of postnatal growth. Two recent longitudinal studies of children who had been stunted in both birthweight and birthlength have shown that these deficits remain evident through early [20] and late childhood [24]. However, neither of these investigators singled out infants from women with preeclampsia as contributing significantly to the population of infants with IUGR.

Our findings suggest that the postnatal growth of infants of women with preeclampsia may require special monitoring. Additional long term studies are needed to determine if twin children of mothers with preeclampsia require enhanced nutrition postnatally to assure attainment of normal maturational milestones for weight and height. IUGR in weight and length may manifest itself only in extreme cases (ie, multiple gestation), and there may be an adequate margin of safety in the singleton intrauterine environment to offset the potential adverse effects of both inadequate early weight gain and preeclampsia. Further clinical research is needed in both singletons and twins to confirm or refute these results. If validated, the childhood growth of infants who have experienced an intrauterine environment compromised by preeclampsia should be monitored and nutritionally enriched to ensure optimal recovery and normal long term development.

Presented in part at the VIIth World Congress of Hypertension in Pregnancy, Perugia, Italy, October, 1990.

\section{REFERENCES}

1. Abrams B, Newman V, Key T, Parker J (1989): Maternal weight gain and preterm delivery. Obstet Gynecol 74:577-583.

2. ACOG Technical Bulletin: Management of preeclampsia. No. 91, February (1986).

3. Benirshke K, Drescoll S (1974): Pathology of the Human Placenta. New York: SpringerVerlag, pp. 325-327.

4. Bingham AW (1932): The prevention of obstetric complications by diet and exercise. Am J Obstet Gynecol 23:38-44.

5. Blickstein I, Shoham-Schwartz Z, Lancet M, Borenstein R (1987): Characterization of the growth-discordant twin. Obstet Gynecol 70:11-14 
6. Brown JE, Schloesser PT (1990): Prepregnancy weight status, prenatal weight gain, and the outcome of term twin gestations. Amer J Obstet Gynecol 162:182-186.

7. Hannah, CR (1925): Weight during pregnancy with observations and statistics. Am J Obstet Gynecol 9:854-863.

8. Hediger ML, Scholl TO, Belsky DH, Ances IG, Salmon RW (1989): Patterns of weight gain in adolescent pregnancy: Effects on birth weight and preterm delivery. Obstet Gynecol 74:6-12.

9. Long PA, Oats, JN (1987): Preeclampsia in twin pregnancy. Severity and pathogenesis. Austr N Z J Obstet Gynecol 27:1-5.

10. Luke B, Witter FR, Abbey H, Feng T, Namnoun AB, Johnson TRB (1991): Gestational agespecific birth weights of twins versus singletons. Acta Genet Med Gemellol 40:69-76,

11. Mabie BC, Sibai BM (1987): Hypertensive states of pregnancy. In Pernoll ML, Benson RC (eds): Current Obstetric \& Gynecol Diagnosi \& Treatment, (6th ed) Norwalk, Conn: Appleton \& Lange, pp 340-352.

12. McMullan PF, Marivate M (1984): Pregnancy-induced hypertension in twin pregnancy. $\mathrm{Br} \mathbf{J}$ Obstet Gynecol 91:240-243.

13. O'Brien WF, Knuppel RA, Scerbo JC, Rattan PK (1986): Birth weight in twins: An analysis of discordancy and growth retardation. Obstet Gynecol 67:483-486.

14. Pederson AL, Worthington-Roberts B, Hickok DE (1989): Weight gain patterns during twin gestation. J Am Diet Assoc 89:642-646.

15. Scholl TO, Hediger ML, Ances IG, Belsky DH, Salmon RW (1990): Weight gain during pregnancy in adolescence: Predictive ability of early weight gain. Obstet Gynecol 75:948-953.

16. Sheehan HL, Lynch JB (1973): Pathology of Toxemia of Pregnancy. Baltimore: Williams \& Wilkins, pp. 678-679.

17. Stander HJ, Pastore JB (1940): Weight changes during pregnancy and puerperium. Am J Obstet Gynecol 39:928-937.

18. Stevens-Simon C, McAnarney ER, Coulter MP (1986): How accurately do pregnant adolescents estimate their weight prior to pregnancy J Adoles Hlth Care 7:250-254.

19. Stewart AL (1982): The reliability and validity of self-reported weight and height. J Chron Dis 35:259-309.

20. Stouffer A, Burns WJ, Burns KA, Melamed J, Herman CE (1988): Early developmental progress of preterm twins discordant for birthweight and risk. Acta Genet Med Gemellol 37:81-87.

21. Tanner JM (1978): Fetus Into Man. Boston, Massachusetts: Harvard University Press, pp. 40-42.

22. Tompkins WT, Wiehl DG, Mitchell McN R (1955): The underweight patient as an increased obstetric hazard. Am J Obstet Gynecol 69:114-123.

23. Young M (1981): Placental factors and fetal nutrition. Am J Clin Nutr 34:738-43.

24. Villar J, Belizan JM (1982): The timing factor in the pathophysiology of the intrauterine growth retardation syndrome. Obstet Gynecol Survey 37:499-506.

Correspondence: Louis Keith, M.D., Northwestern University Medical School, Department of Obstetrics and Gynecology, 333 East Superior Street, Suite 464, Chicago, IL 60611, USA. 